\title{
HYDROGEN PEROXIDE PROLONGS MITOTIC ARREST IN A DOSE DEPENDENT MANNER AND INDEPENDENTLY OF THE SPINDLE ASSEMBLY CHECKPOINT ACTIVITY IN SACCHAROMYCES CEREVISIAE
}

\author{
Pinar Buket Atalay, ${ }^{*}$ Oyku Asci, ${ }^{2}$ \\ FATIH ONER Kaya ${ }^{3}$ and Bilge GuvenC TunA ${ }^{4}$ \\ ${ }^{1}$ Department of Medical Biology and Genetics, Faculty of Medicine, Maltepe University, \\ Istanbul, Turkey \\ ${ }^{2}$ Department of Clinical Embryology, Graduate School of Health Sciences, Maltepe University, \\ Istanbul, Turkey \\ ${ }^{3}$ Department of Internal Medicine, Faculty of Medicine, Maltepe University, Istanbul, Turkey \\ ${ }^{4}$ Department of Biophysics, School of Medicine, Yeditepe University, \\ Istanbul, Turkey
}

(Received: July 17, 2017; accepted: September 13, 2017)

\begin{abstract}
Oxidative stress and chromosome missegregation are important factors that are linked to aneuploidy. A major reason for chromosome missegragation is the inappropriate activity of the spindle assembly checkpoint (SAC), a conserved surveillance mechanism that monitors the state of kinetochore-microtubule attachments to ensure equal chromosome segregation in mitosis. SAC-activation induces a prolonged mitotic arrest. Mitosis is considered the most vulnerable cell cycle phase to several external signals, therefore increasing the time cells spent in this phase via mitotic arrest induction by SAC-activating agents is favorable for cancer therapy. Cancer cells also display elevated oxidative stress due to abnormally high production of reactive oxygen species (ROS). However, the effect of increased oxidative stress on the duration of mitotic arrest remains largely unknown. In this study, we investigated the effect of $\mathrm{H}_{2} \mathrm{O}_{2}$-induced oxidative stress on the mitotic arrest induced by a SAC-activating agent (nocodazole) in Saccharomyces cerevisiae. Our data suggest that oxidative stress prolongs SAC-activation induced mitotic arrest in a dose dependent manner. We, in addition, investigated the effect of $\mathrm{H}_{2} \mathrm{O}_{2}$ treatment on the mitotic arrest induced independently of SAC-activation by using a conditional mutant $(c d c 23)$ and showed that the effect of $\mathrm{H}_{2} \mathrm{O}_{2}$-induced oxidative stress on mitotic arrest is independent of the SAC activity.
\end{abstract}

Keywords: Spindle assembly checkpoint - Oxidative stress - Mitotic arrest - Cancer - Saccharomyces cerevisiae

\section{INTRODUCTION}

Equal segregation of chromosomes into two daughter cells during mitosis is critical for maintaining genomic stability. Failure in the regulation of mitosis may lead to an abnormal chromosome number and content in daughter cells, known as aneuploidy [14]. Aneuploidy is a common characteristic of cancer cells. About $90 \%$ of

*Corresponding author; e-mail address: pbd6d@virginia.edu 
solid tumors and $85 \%$ of hematopoietic neoplasias are known to be aneuploid [38]. Not surprisingly, cells have evolved several mechanisms to ensure fidelity of chromosome segregation in mitosis to prevent aneuploidy.

Since uncontrolled chromosome segregation and proliferation are critical factors leading to carcinogenesis, mitosis has been a successful target for cancer therapy. Indeed, two groups of anti-cancer drugs taxanes (paclitaxel/taxol, docetaxel) and vinca alkoloids (vinblastine, vincristine) that have been successfully used in the treatment of several cancers for decades display their anti-tumor activities by interfering with mitotic progression [2]. These drugs disrupt the functional mitotic spindle formation by binding to tubulin, the structural subunit of spindle microtubules. Aberrant spindle formation leads to improper chromosome-spindle microtubule attachments, which activates the spindle assembly checkpoint (SAC) and induces a prolonged mitotic arrest [23]. SAC is an evolutionarily conserved regulatory mechanism that monitors the state of kinetochore-microtubule attachments to ensure equal chromosome segregation in mitosis [31]. SAC gets activated in response to the presence of improperly attached/unattached chromosomes and induces a mitotic arrest by inactivating Cdc20, a substrate specific co-activator of an E3 ubiquitin ligase named anaphase-promoting complex/cyclosome (APC/C). Because APC/CCdc20 triggers metaphase-to-anaphase transition by targeting securin (Pds1 in yeast) for degradation, inhibition of $\mathrm{APC} / \mathrm{C} C \mathrm{Cd} 20$ activity by SAC activation delays anaphase onset through Pds1 stabilization [24]. Aberrant SAC activity through mutations in the checkpoint genes may lead to genomic instability due to premature chromosome segregation in anaphase before all chromosomes are properly attached [1, 22, 37]. Consistent with this, aneuploidy is frequently observed in several tumors with abnormal expression levels of SAC genes $[4,26]$.

Oxidative stress has also been reported to be associated with aneuploidy, therefore carcinogenesis $[6,8,27,32]$. An antioxidant agent (oltipraz) has been shown to have a significant inhibitory effect on aneuploidy in fibroblasts of Li-Fraumeni syndrome patients [15] and overexpression of an antioxidant enzyme (superoxide dismutase) has been reported to significantly decrease aneuploidy in a T cell lymphoma mouse model [33]. Oxidative stress results in the imbalance between the production and destruction of reactive oxygen species (ROS) in the favor of the former [28]. Increased oxidative stress due to abnormally high ROS production has been reported in several types of cancer. Increased ROS levels in cancer cells have been proposed to enhance the oncogenic properties of cancer cells such as proliferation, survival and migration [19] as well as alterations in sensitivity to anticancer agents [25].

Mitotic arrest induction through SAC-activating agents is favorable for cancer treatment, because the arrest increases the time they spend in mitosis, which is considered the most vulnerable phase of the cell cycle to several external factors such as chemical exposure [11] and radiation [30]. However, the effect of increased oxidative stress in cancer cells on the duration of the mitotic arrest induced by SAC activating chemotherapy drugs remains largely unknown. In this study, we investigated the effect of oxidative stress induced by different concentrations of hydrogen peroxide 
$\left(\mathrm{H}_{2} \mathrm{O}_{2}\right)$ on mitotic arrest induced by nocodazole, a SAC activating agent, in Saccharomyces cerevisiae. We demonstrated that $\mathrm{H}_{2} \mathrm{O}_{2}$ treatment of nocodazolearrested cultures led to an increased number of mitotic cells in a dose dependent manner at the end of the course of the experiment compared to the untreated nocodazole-arrested culture, suggesting that oxidative stress prolongs SAC-activation dependent mitotic arrest in a dose dependent manner. We also investigated whether the prolonged mitotic arrest observed in the $\mathrm{H}_{2} \mathrm{O}_{2}$ treated cultures was due to the SAC activity. We showed that the $\mathrm{H}_{2} \mathrm{O}_{2}$ treatment also increased the number of mitotic cells in cultures arrested in mitosis through an $\mathrm{APC} / \mathrm{C}$ mutation $(c d c 23)$ in a dose dependent manner, suggesting that $\mathrm{H}_{2} \mathrm{O}_{2}$ induced oxidative stress increases the duration of the mitotic arrest in a dose dependent manner and independently of the SAC activity.

\section{MATERIALS AND METHODS}

\section{Strains and growth conditions}

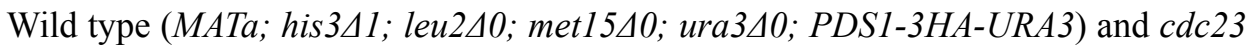
mutant (MATa leu2 ura3 his3 met3 PGAL1-PDS1-MDB1::LEU2 cdc23) S. cerevisiae strains, a very kind gift from Dr. Daniel Burke, were used in this study. Yeast cells were maintained on YPD agar plates containing 2\% (wt/vol) glucose, $1 \%(\mathrm{wt} / \mathrm{vol})$ yeast extract, $2 \%(\mathrm{wt} / \mathrm{vol})$ peptone, and $2 \%(\mathrm{wt} / \mathrm{vol})$ agar and cultured in liquid YPD medium $(2 \% \mathrm{wt} / \mathrm{vol})$ glucose, $1 \%(\mathrm{wt} / \mathrm{vol})$ yeast extract and $2 \%(\mathrm{wt} / \mathrm{vol})$ peptone). Wild type strain was cultured at $30{ }^{\circ} \mathrm{C}$. Temperature sensitive mutant strain was incubated at $23{ }^{\circ} \mathrm{C}$ before being shifted to the restrictive temperature of $35^{\circ} \mathrm{C}$.

\section{Induction of mitotic arrest and oxidative stress}

For SAC activation-dependent mitotic arrest induction, wild type yeast cells grown to early mid-logarithmic phase $\left(\right.$ O. $\left._{600}=\sim 0.3\right)$ were incubated with $15 \mu \mathrm{g} / \mathrm{ml} \mathrm{noco-}$ dazole (Sigma) in liquid YPD on a mechanical shaker $(175 \mathrm{rpm})$ at $30{ }^{\circ} \mathrm{C}$ for 3 hours. To induce mitotic arrest independently of SAC activation, temperature sensitive $c d c 23$ mutants were grown to early mid-log phase $\left(\mathrm{O}^{-\mathrm{D}_{600}}=\sim 0.3\right)$ in liquid YPD on a mechanical shaker $(175 \mathrm{rpm})$ at $23{ }^{\circ} \mathrm{C}$ and shifted to $35^{\circ} \mathrm{C} 3$ hours prior to the $\mathrm{H}_{2} \mathrm{O}_{2}$ treatments. In both SAC-activation dependent ( 3 hour incubation in the presence of nocodazole) and independent ( 3 hour incubation at the restrictive temperature) mitotic arrest inductions, the efficiency of the mitotic arrest was monitored under the light microscope. Presence of $>70 \%$ of large budded cells was considered an efficient mitotic arrest. For wild type cells, $0 \mathrm{mM}, 0.2 \mathrm{mM}, 1 \mathrm{mM}, 3 \mathrm{mM}, 10 \mathrm{mM}$ or $200 \mathrm{mM}$ $\mathrm{H}_{2} \mathrm{O}_{2}$ were directly added to the mitotically arrested cultures (T0) and incubated on a mechanical shaker $(175 \mathrm{rpm})$ at $30^{\circ} \mathrm{C}$ for 3 hours. $c d c 23$ mutants were treated with $0 \mathrm{mM}, 0.2 \mathrm{mM}, 3 \mathrm{mM}$ or $10 \mathrm{mM} \mathrm{H}_{2} \mathrm{O}_{2}$ and incubated on a mechanical shaker (175 
rpm) at $23{ }^{\circ} \mathrm{C}$ for 3 hours. Samples were taken from each culture at every hour for 3 hours (T1, T2, T3).

\section{Western Blot Analysis}

Protein extracts were prepared from samples taken at T0, T1, T2, and T3 by the $\mathrm{NaOH}$ method as described previously [16]. Total protein extracts were transferred to immobilon PVDF membrane (Millipore). The membranes were blocked in 5\% dry fat-free milk in 1X PBS for 1 hour at room temperature and probed with anti-HA (Abcam) and anti-Pgk1 (Abcam) antibodies overnight at $4{ }^{\circ} \mathrm{C}$ for Pds1-3HA and Pgk1 (loading control) detection, respectively. Following the primary antibody incubations, membranes were washed three times with $1 \mathrm{X}$ PBS and incubated with the appropriate HRP-conjugated secondary antibodies in 5\% dry fat-free milk in 1X PBS for 1 hour at room temperature. Membranes were washed three times with 1X PBS after the secondary antibody incubation. Following the washes, the blots were stained with ECL (WesternBright Sirius HRP substrate, Advansta), exposed to medical X-ray, MXBE blue film (Carestream) and developed manually. Pictures of the films were taken on a light box. Pds1-HA levels in at least two independent experiments were analyzed by western blot.

\section{Detection of Reactive Oxygen Species (ROS)}

Intracellular ROS levels were examined as reported previously [20]. Briefly, $200 \mu 1$ of cells were collected at each time point and resuspended in $200 \mu \mathrm{l}$ of fresh YPD medium. The cells were incubated with $10 \mu \mathrm{g} / \mathrm{ml} 2^{\prime}, 7^{\prime}$-dichlorodihydrofluorescein diacetate (H2DCFDA; Molecular Probes) at $30^{\circ} \mathrm{C}$ for 40 minutes. Five $\mu 1$ of cells were applied onto microscope slides immediately after the incubation and examined under a fluorescence microscope (Leica DM1000 LED, Leica Microsystems, Germany, excitation at $495 \mathrm{~nm}$ and emission at $525 \mathrm{~nm}$ ). At least 200 cells were examined for each sample at T0 and T3, and scored as "fluorescent" or "non-fluorescent". The experiment was conducted at least in triplicate for each $\mathrm{H}_{2} \mathrm{O}_{2}$ concentration.

\section{DAPI staining}

Samples collected at each time point were fixed with $3.7 \%(\mathrm{v} / \mathrm{v})$ formaldehyde for 1-1.5 hours at room temperature. After the fixation, samples were washed twice with $\mathrm{dH}_{2} \mathrm{O}$, resuspended in $\mathrm{dH}_{2} \mathrm{O}$ and stored at $4{ }^{\circ} \mathrm{C}$ until staining. For staining, the cells were centrifuged and fixed with $70 \%(\mathrm{v} / \mathrm{v})$ ethanol for 30 minutes at room temperature. Ethanol fixed cells were washed once with $\mathrm{dH}_{2} \mathrm{O}$ and resuspended in water. Five $\mu \mathrm{l}$ of cells were loaded onto slides and stained with DAPI (4',6-diamidino-2-phe- 
nylindole) $(2 \mu \mathrm{g} / \mathrm{ml})$ in Vectashield mounting medium (Vector, Burlingame, CA). For each time point, at least 200 cells were examined for budding morphology and DAPI staining under a fluorescence microscope (Leica DM1000 LED, Leica Microsystems, Germany) and scored as "large budded with 1 nucleus", "large budded with 2 nuclei", or "other". The experiment was conducted at least three times for each $\mathrm{H}_{2} \mathrm{O}_{2}$ concentration and the percentage of cells that were "large budded with 1 nucleus" was reported.

\section{Spotting assay}

Samples were taken right after the 3-hour nocodazole incubation - as soon as the $\mathrm{H}_{2} \mathrm{O}_{2}$ treatment - (T0) and after the 3-hour incubation with $0 \mathrm{mM}, 0.2 \mathrm{mM}, 1 \mathrm{mM}$, $3 \mathrm{mM}, 10 \mathrm{mM}$ and $200 \mathrm{mM} \mathrm{H}_{2} \mathrm{O}_{2}$ (T3). Ten fold serially diluted aliquots of each sample were prepared and $5 \mu \mathrm{l}$ from each aliquot was spotted on the YPD plates. Pictures were taken after the incubation at $30{ }^{\circ} \mathrm{C}$ for 2 days.

\section{Statistical analysis}

Data are expressed as the mean standard deviation (std). Statistical analyses were done by student's t-test. Differences were considered statistically significant at $p<0.05, n$ values represent the number of independent experiments.

\section{RESULTS}

\section{Sensitivity of nocodazole arrested cells to oxidative stress}

We used hydrogen peroxide $\left(\mathrm{H}_{2} \mathrm{O}_{2}\right)$ to induce ROS accumulation, thus trigger oxidative stress; and nocodazole to induce SAC activation-dependent mitotic arrest in a wild type Saccharomyces cerevisiae strain. Early mid-logarithmic phase cells $\left(\mathrm{OD}_{600}=\sim 0.3\right)$ were treated with nocodozole $(15 \mu \mathrm{g} / \mathrm{ml})$ for 3 hours $(\mathrm{T} 0)$. Nocodazole is a spindle poison, which activates the SAC and induces a SAC activation-dependent metaphase arrest by perturbing the kinetochore-microtubule attachments. Immediately after the 3 hour-nocodazole arrest $0 \mathrm{mM}, 0.2 \mathrm{mM}, 1 \mathrm{mM}, 3 \mathrm{mM}, 10 \mathrm{mM}$ or $200 \mathrm{mM}$ $\mathrm{H}_{2} \mathrm{O}_{2}$ was added to each culture $\left(\mathrm{OD}_{600}=\sim 0.8\right)$ (T0) and incubated for 3 hours (T3).

First, $\mathrm{H}_{2} \mathrm{O}_{2}$-induced ROS production was examined in each culture by the H2DCFDA assay. Carboxy-H2DCFDA is a non-fluorescent reagent, but in the presence of ROS it gets oxidized and becomes green fluorescent. We observed that the intracellular ROS levels after the nocodazole treatment (T0) was the same among cultures that have just been treated with different $\mathrm{H}_{2} \mathrm{O}_{2}$ concentrations, as the percentage of fluorescent cells in $0.2 \mathrm{mM}, 1 \mathrm{mM}, 3 \mathrm{mM}, 10 \mathrm{mM}$ or $200 \mathrm{mM} \mathrm{H}_{2} \mathrm{O}_{2}$ treated cultures were not significantly different compared to the untreated control at $\mathrm{T} 0$ 

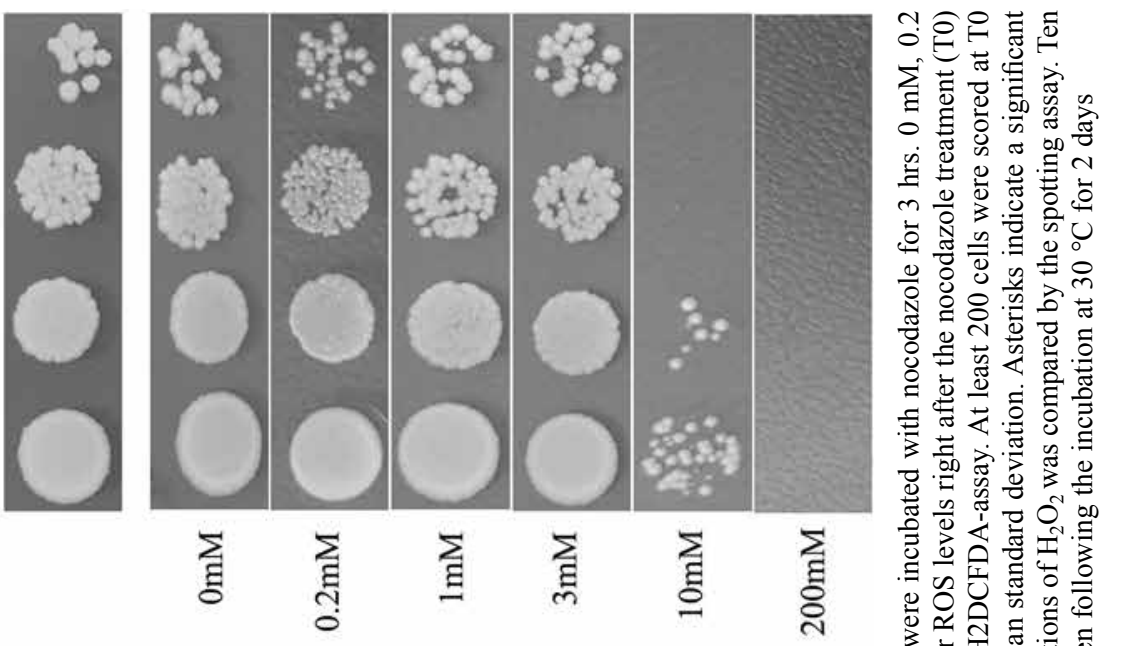

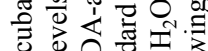

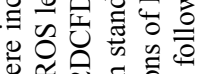

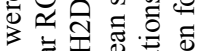

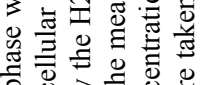

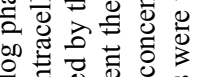

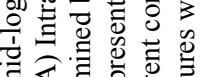

ติ

E

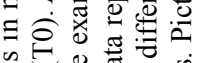
氙记

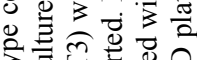

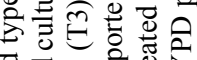

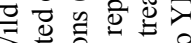

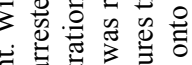
苛志哥主声 焉券 $\overline{\overline{0}}$ 巳

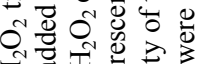

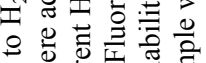

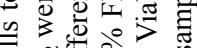

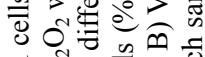

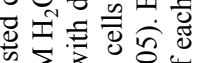

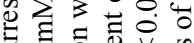

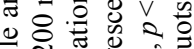

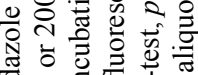

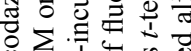
范范尝 응요웧

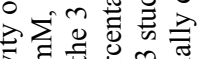

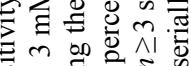
靠

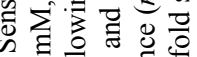
- 二司向

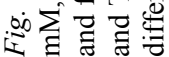


( $p>0.05$ ). 3 hours after the $\mathrm{H}_{2} \mathrm{O}_{2}$ treatments (T3), percentage of fluorescent cells in cultures treated with either $10 \mathrm{mM}$ or $200 \mathrm{mM} \mathrm{H}_{2} \mathrm{O}_{2}$ (76.7\% and $99 \%$, respectively) were significantly higher compared to the untreated control $(12.4 \%)\left({ }^{*} p<0.05\right)$. Whereas, percentage of fluorescent cells were not significantly different in the cultures treated with $0.2 \mathrm{mM}, 1 \mathrm{mM}$ or $3 \mathrm{mM} \mathrm{H}_{2} \mathrm{O}_{2}$ relative to the control $(p>0.05)$ (Fig. 1A). These data suggest that lower $\mathrm{H}_{2} \mathrm{O}_{2}$ concentrations $(0.2 \mathrm{mM}, 1 \mathrm{mM}$ and 3 $\mathrm{mM}$ ) do not lead to a significant intracellular ROS accumulation, whereas higher concentrations $(10 \mathrm{mM}, 200 \mathrm{mM})$ significantly increase ROS levels in nocodazolearrested cultures compared to the untreated arrested control.

Next, we investigated the sensitivity of nocodazole-arrested cells to different $\mathrm{H}_{2} \mathrm{O}_{2}$ concentrations by the spotting assay. Early mid-log phase cells $\left(\mathrm{OD}_{600}=\sim 0.3\right)$ were treated with nocodazole for 3 hours (T0). Arrested cultures were then treated with 0 $\mathrm{mM}, 0.2 \mathrm{mM}, 1 \mathrm{mM}, 3 \mathrm{mM}, 10 \mathrm{mM}$ or $200 \mathrm{mM} \mathrm{H}_{2} \mathrm{O}_{2}$ for 3 hours (T3). Following the $\mathrm{H}_{2} \mathrm{O}_{2}$ treatments, 10 fold serial dilutions of each culture were spotted $(5 \mu \mathrm{l})$ onto YPD plates. After a 2-day incubation at $30^{\circ} \mathrm{C}$, viability of the cultures was compared (Figure 1B). Consistent with the ROS results, after the 3-hour incubation with lower concentrations of $\mathrm{H}_{2} \mathrm{O}_{2}(0.2 \mathrm{mM}, 1 \mathrm{mM}, 3 \mathrm{mM})$ were not very different by means of viability compared to the untreated control, whereas treatment with higher $\mathrm{H}_{2} \mathrm{O}_{2}$ concentrations $(10 \mathrm{mM}, 200 \mathrm{mM})$ resulted in a decreased viability compared to the control (Fig. 1B, T3). Specifically, $200 \mathrm{mM} \mathrm{H}_{2} \mathrm{O}_{2}$ treatment led to a complete loss of viability. Therefore, we determined $200 \mathrm{mM} \mathrm{H}_{2} \mathrm{O}_{2}$ to be the lethal dose for our experiments.

\section{Effect of oxidative stress on nocodazole-induced mitotic arrest}

In order to investigate the effects of oxidative stress on the duration of SAC activation-dependent mitotic arrest, wild type cells $\left(\mathrm{O} . \mathrm{D}_{600}=\sim 0.3\right)$ were treated with nocodazole for 3 hours. After the nocodazole incubation (T0), cultures $\left(\mathrm{O}^{-\mathrm{D}_{600}}=\sim 0.8\right)$ were treated with $0 \mathrm{mM}, 0.2 \mathrm{mM}, 1 \mathrm{mM}, 3 \mathrm{mM}$ or $10 \mathrm{mM} \mathrm{H}_{2} \mathrm{O}_{2}$ and samples were collected at every hour for 3 hours (T1, T2, T3). Mitotic arrest phenotype was monitored morphologically by DAPI staining and biochemically by western blot analysis at each time point (Fig. 2).

Cycling S. cerevisiae cells have either no buds or have buds smaller than $1 / 3$ of the mother cell. Metaphase arrested cells, on the other hand, can be distinguished by their large budded (approximately the same size with the mother cell) phenotype with unsegregated chromosomes (one nucleus) $[10,17]$. Samples collected at each time point were stained with DAPI, examined for budding and nuclear morphology under a fluorescent microscope and scored as "large budded with one nucleus", "large budded with two nuclei" or "other (unbudded and small budded)" (Fig. 2A), where "large budded with one nucleus" morphology represents metaphase cells. We observed that majority of the untreated cells completed metaphase 3 hours after the nocodazole treatment as only $8.2 \%$ of the untreated cells were large budded with a single nucleus at T3. Percentage of large budded cells with one nucleus in $0.2 \mathrm{mM}(9.3 \%)$ and $1 \mathrm{mM}$ 
(10.1\%) $\mathrm{H}_{2} \mathrm{O}_{2}$ treated cultures at $\mathrm{T} 3$ were not significantly different than that of the untreated control $(8.2 \%, p>0.05)$. However, percent metaphase cells at $\mathrm{T} 3$ in cultures treated with $3 \mathrm{mM}(29.7 \%)$ and $10 \mathrm{mM}(70.4 \%) \mathrm{H}_{2} \mathrm{O}_{2}$ were significantly higher compared to the untreated control $(p<0.05)$ (Fig. 2B). These data together suggest that higher sublethal concentrations of $\mathrm{H}_{2} \mathrm{O}_{2}(3 \mathrm{mM}$ and $10 \mathrm{mM})$ prolong $\mathrm{SAC}$-activation dependent mitotic arrest, whereas lower sublethal concentrations $(0.2 \mathrm{mM}$ and $1 \mathrm{mM})$ do not have a significant effect on the duration SAC-dependent mitotic arrest.

Degradation of securin/ Pds1 (also known as the "anaphase inhibitor") triggers the metaphase-to-anaphase transition; therefore it is a widely accepted biochemical marker for the anaphase onset. In cycling cells, Pds1 levels peak in metaphase and decrease as the cells proceed into anaphase, whereas in mitotically arrested cells Pds 1 levels remain stable. To examine the effect of oxidative stress on SAC-activation dependent mitotic arrest biochemically, Pds1 levels in untreated and $0.2 \mathrm{mM}, 3 \mathrm{mM}$ or $10 \mathrm{mM} \mathrm{H}_{2} \mathrm{O}_{2}$ treated nocodazole-arrested cells were monitored at every hour for 3 hours by western blot analysis (Fig. 2C). A high level of Pds1 was detected in each culture right after the nocodazole treatment (T0), consistent with an efficient metaphase arrest. Pds1 levels in untreated and $0.2 \mathrm{mM} \mathrm{H}_{2} \mathrm{O}_{2}$ treated cultures decreased significantly after the 3-hour incubation with $\mathrm{H}_{2} \mathrm{O}_{2}$ (T3), indicating that $0.2 \mathrm{mM} \mathrm{H}_{2} \mathrm{O}_{2}$ treatment does not sustain the mitotic arrest. On the other hand, Pds1 levels in cultures treated with $3 \mathrm{mM}$ or $10 \mathrm{mM} \mathrm{H}_{2} \mathrm{O}_{2}$ remained stable during the course of the experiment, suggesting that higher concentrations of $\mathrm{H}_{2} \mathrm{O}_{2}$ maintain $\mathrm{SAC}$-activation dependent mitotic arrest (Fig. 2B).

\section{Effect of oxidative stress on SAC activation-independent mitotic arrest}

Next, we wanted to know whether the effect of $\mathrm{H}_{2} \mathrm{O}_{2}$-induced oxidative stress on nocodazole-arrested cells was through SAC activity or it was just a result of cells being in mitosis. To test this, we induced a mitotic arrest that is independent of SAC activation by using a temperature sensitive $c d c 23$ mutant strain.

$\mathrm{Cdc} 23$ is a core subunit of the anaphase promoting complex/cyclosome (APC/C), which is an E3 ubiquitin ligase that targets several proteins for degradation. Degradation of Pds1 in metaphase depends on the association of APC/C with a substrate specific activator, Cdc20. SAC activation induces a metaphase arrest by targeting $\mathrm{Cdc} 20$ to inactivate the $\mathrm{APC} / \mathrm{C}$ and stabilize Pds1. $c d c 23$ conditional mutation leads to inactivation of $\mathrm{APC} / \mathrm{C}$ at the restrictive temperature [12], thus induces a metaphase arrest that is independent of SAC activation.

$C d c 23$ cells grown to early mid-log $\left(\mathrm{O}^{-\mathrm{D}_{600}}=\sim 0.3\right)$ at the permissive temperature $\left(23{ }^{\circ} \mathrm{C}\right)$ were shifted to restrictive temperature $\left(35^{\circ} \mathrm{C}\right)$ for 3 hours to induce SACactivation independent mitotic arrest. After the 3 -hour incubation at $35^{\circ} \mathrm{C}(\mathrm{T} 0)$, cultures $\left(\mathrm{O}^{-\mathrm{D}_{600}}=\sim 0.8\right)$ were treated with $0 \mathrm{mM}, 0.2 \mathrm{mM}, 3 \mathrm{mM}$ or $10 \mathrm{mM} \mathrm{H}_{2} \mathrm{O}_{2}$ and samples were collected at every hour for 3 hours $(\mathrm{T} 1, \mathrm{~T} 2, \mathrm{~T} 3)$ at $23{ }^{\circ} \mathrm{C}$. Mitotic arrest phenotype of the samples was monitored by DAPI staining (Fig. 2A). Following the 3 hour-incubation at $35{ }^{\circ} \mathrm{C}, 69.5 \%$ of the cells were arrested in metaphase as "large 


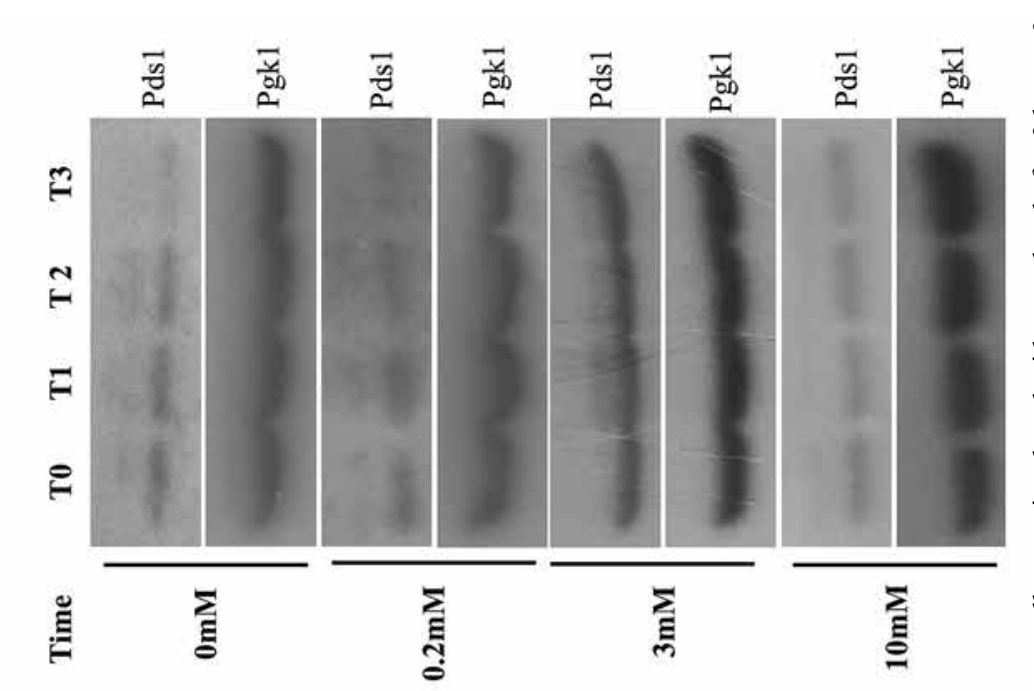

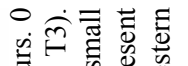

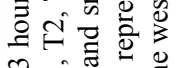

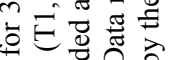

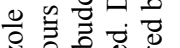

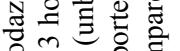

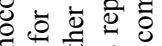

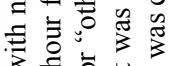

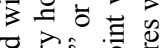

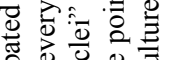

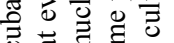
元

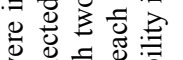

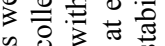

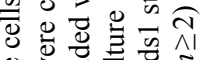

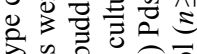

0

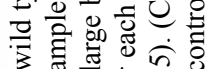
卷

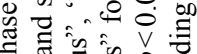
क人ิ

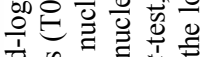
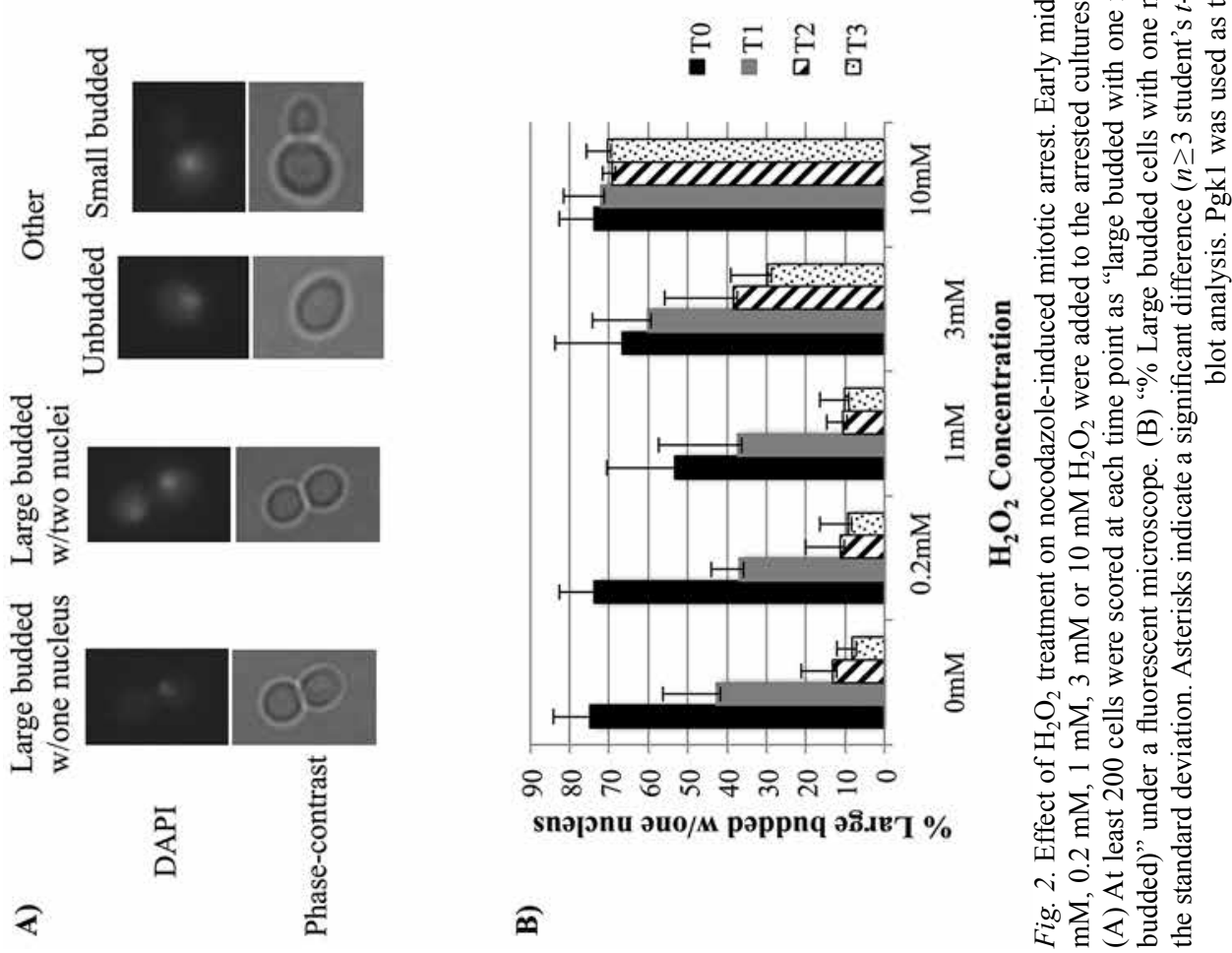


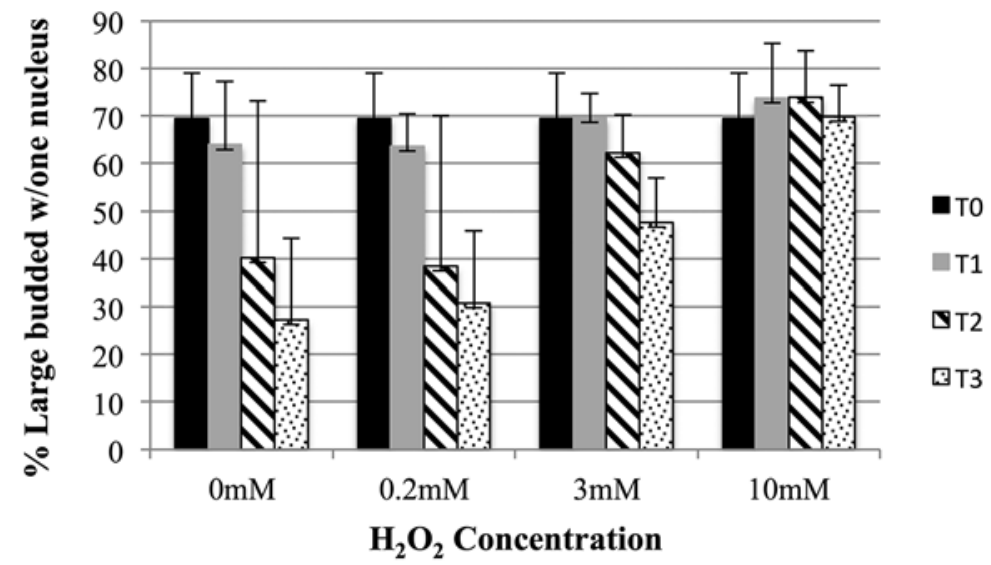

Fig. 3. Effect of $\mathrm{H}_{2} \mathrm{O}_{2}$ treatment on $\mathrm{SAC}$ activation-independent mitotic arrest. $c d c 23$ conditional mutant strain grown to early mid-log at the permissive temperature $\left(23^{\circ} \mathrm{C}\right)$ was shifted to restrictive temperature $\left(35^{\circ} \mathrm{C}\right)$ for 3 hours. Following the 3 hour-incubation at $35^{\circ} \mathrm{C}(\mathrm{T} 0)$, cultures were treated with $0 \mathrm{mM}, 0.2$ $\mathrm{mM}, 3 \mathrm{mM}$ or $10 \mathrm{mM} \mathrm{H}_{2} \mathrm{O}_{2}$. Samples collected at every hour for 3 hours (T1, T2, T3) at $23{ }^{\circ} \mathrm{C}$ were stained with DAPI and scored as "large budded with one nucleus", "large budded with two nuclei" or "other". Experiments were performed in triplicate $(n=3)$ for each $\mathrm{H}_{2} \mathrm{O}_{2}$ treatment and the average values

for "\% Large budded cells with one nucleus" were reported with the indicated standard deviations

budded cells with a single nucleus" (Fig. 3, T0), indicating an efficient metaphase arrest. 3 hours after the shift to the restrictive temperature, $42.3 \%$ of the untreated control cells exited from APC/C inactivation induced mitotic arrest, as only $27.2 \%$ of the untreated culture was large budded with a single nucleus at T3. Very similar to the untreated control, only $30.8 \%$ of the $0.2 \mathrm{mM} \mathrm{H}_{2} \mathrm{O}_{2}$ treated culture was in metaphase at T3. On the other hand, majority of the $3 \mathrm{mM}$ and $10 \mathrm{mM}$ treated cells $(47.6 \%$ and $69.8 \%$, respectively) remained arrested in metaphase at $\mathrm{T} 3$ (Fig. 3, T3). These data imply that treatment with higher sublethal concentrations of $\mathrm{H}_{2} \mathrm{O}_{2}$ maintain the mitotic arrest induced independently of SAC-activation.

\section{DISCUSSION}

Appropriate activity of the spindle assembly checkpoint (SAC) and oxidative stress are two important factors that have been shown to be associated with aneuploidy, a hallmark of cancer cells. Two groups of chemotherapeutics, which are successfully used in the treatment of several types of cancer (vinca alkaloids and taxanes), inhibit cancer cell proliferation by inducing a SAC-activation dependent mitotic arrest. Besides preventing cancer cell proliferation by blocking the cell cycle, mitotic arrest induction also increases the time cells spend in mitosis, which is considered the most vulnerable cell cycle phase to several external factors including exposure to radiation [30] and chemicals [11], thus is favorable for cancer therapy. Many SAC-activating 
anticancer drugs are also known to increase intracellular ROS levels leading to oxidative stress in cancer cells [34]. Aside from the ROS induction by these anticancer drugs, cancer cells themselves produce abnormally high levels of ROS.

Although the effect of oxidative stress on cell cycle progression is well studied and has been shown to induce cell cycle arrest in both yeast and mammalian cells [13, 21, 29], its effect on mitotically arrested cells remains largely unknown. To the best of our knowledge, the only study investigating the effects of oxidative stress on SACactivated mitotic arrest was performed in HeLa cells. Data from this study suggested that treatment with low $\mathrm{H}_{2} \mathrm{O}_{2}$ concentrations override the SAC-activated mitotic arrest, whereas higher concentrations do not significantly affect the SAC-dependent arrest [3]. In the present study, we investigated the effect of $\mathrm{H}_{2} \mathrm{O}_{2}$-induced oxidative stress on SAC-activation dependent mitotic arrest triggered by nocodazole treatment in Saccharomyces cerevisiae. Our data revealed that higher sublethal concentrations of $\mathrm{H}_{2} \mathrm{O}_{2}$ prolong $\mathrm{SAC}$-activation dependent mitotic arrest in a dose dependent manner compared to the untreated control. One of the major differences between the two studies, which may explain the different conclusions, is the different cell types used. Unlike mammalian cells, yeast cells have cell walls. Therefore, sensitivity of yeast cells to $\mathrm{H}_{2} \mathrm{O}_{2}$ is very different than that of mammalian cells; $\mathrm{H}_{2} \mathrm{O}_{2}$ concentrations that have been considered "high" in HeLa cells may not have any significant effect on mid-log phase yeast cells. Another major difference between the two studies is that we treated yeast cells with the SAC-activating drug only for once during the course of the experiment, which allowed untreated control cells to exit the mitotic arrest at the end of the experiment. On the other hand D'Angiolella et al. performed their experiments in the continuous presence of SAC-activating drug, thus maintained the SAC-activation induced mitotic arrest during the course of their experiment [3].

In this study, we also asked whether the prolonged mitotic arrest in $\mathrm{H}_{2} \mathrm{O}_{2}$ treated cells was dependent on the SAC-activity. To test this, we treated the $c d c 23$ conditional mutant strain, which arrests in mitosis at the restrictive temperature independent of the SAC-activity and showed that high concentrations of $\mathrm{H}_{2} \mathrm{O}_{2}$ also prolonged mitotic arrest induced independently of SAC-activation.

Our data together suggest that $\mathrm{H}_{2} \mathrm{O}_{2}$-induced oxidative stress prolongs mitotic arrest in a dose dependent manner and the effect of oxidative stress on mitotically arrested cells is independent of the SAC activity. Recent studies have revealed a crosstalk between the DNA damage response (DDR) and the SAC, suggesting that the two checkpoints function together throughout the cell cycle to ensure genomic stability. Indeed, several DDR components have been shown to be required for efficient activation of the SAC in response to improper attachments in metaphase $[5,18]$. Oxidative stress activates DDR through DNA damage induction [9] and induces a mitotic arrest [36]. Rad9, a member of DDR in yeast, has been shown to be required for the oxidative stress induced mitotic arrest [7]. These studies together imply that the effect of oxidative stress on mitotically arrested cells might be associated with the DDR activity. Further studies are needed to be performed with mitotically arrested DDR mutants to test this possibility. 


\section{ACKNOWLEDGEMENTS}

We thank Dr. Daniel J. Burke (North Carolina State University, College of Sciences, Department of Biological Sciences) for kindly sending us the $S$. cerevisiae strains. This study was supported by the Scientific and Technological Research Council of Turkey (TUBITAK) with the project number: 114S094.

\section{REFERENCES}

1. Ando, K., Kakeji, Y., Kitao, H., Iimori, M., Zhao, Y., Yoshida, R., Oki, E., Yoshinaga, K., Matumoto, T., Morita, M., Sakaguchi, Y., Maehara, Y. (2010) High expression of BUBR1 is one of the factors for inducing DNA aneuploidy and progression in gastric cancer. Cancer Sci. 101, 639-645.

2. Chan, K. S., Koh, C. G., Li, H. Y. (2012) Mitosis-targeted anti-cancer therapies: where they stand. Cell Death Dis. 3, e411-

3. D’Angiolella, V., Santarpia, C., Grieco, D. (2007) Oxidative stress overrides the spindle checkpoint. Cell Cycle 6, 576-579.

4. Draviam, V. M., Xie, S., Sorger, P. K. (2004) Chromosome segregation and genomic stability. Curr. Opin. Genet. Dev. 14, 120-125.

5. Duxin, J. P., Walter, J. C. (2015) What is the DNA repair defect underlying Fanconi anemia? Curr. Opin. Cell Biol. 37, 49-60.

6. Estrada, J. C., Torres, Y., Benguría, A., Dopazo, A., Roche, E., Carrera-Quintanar, L., Pérez, R. A., Enríquez, J. A., Torres, R., Ramírez, J. C., Samper, E., Bernad, A. (2013) Human mesenchymal stem cell-replicative senescence and oxidative stress are closely linked to aneuploidy. Cell Death Dis. 4, e691-

7. Flattery-O’Brien, J. A., Dawes, I. W. (1998) Hydrogen peroxide causes RAD9-dependent cell cycle arrest in G2 in Saccharomyces cerevisiae whereas menadione causes G1 arrest independent of RAD9 function. J. Biol. Chem. 273, 8564-8571.

8. Gorla, G. R., Malhi, H., Gupta, S. (2001) Polyploidy associated with oxidative injury attenuates proliferative potential of cells. J. Cell Sci. 114, 2943-2951.

9. Guo, Z., Kozlov, S., Lavin, M. F., Person, M. D., Paull, T. T. (2010) ATM activation by oxidative stress. Science 330, 517-521.

10. Hoyt, M. A., Stearns, T., Botstein, D. (1990) Chromosome instability mutants of Saccharomyces cerevisiae that are defective in microtubule-mediated processes. Mol. Cell. Biol. 10, 223-234.

11. Hughes, A. F. (1950) The effect of inhibitory substances on cell division; a study on living cells in tissue cultures. Q. J. Microsc. Sci. 91, 251-277.

12. Irniger, S., Piatti, S., Michaelis, C., Nasmyth, K. (1995) Genes involved in sister chromatid separation are needed for B-type cyclin proteolysis in budding yeast. Cel1 81, 269-278.

13. Kim, S. Y., Jo, H. Y., Kim, M. H., Cha, Y. Y., Choi, S. W., Shim, J. H., Kim, T. J., Lee, K. Y. (2008) $\mathrm{H}_{2} \mathrm{O}_{2}$-dependent hyperoxidation of peroxiredoxin 6 (Prdx6) plays a role in cellular toxicity via upregulation of iPLA2 activity. J. Biol. Chem. 283, 33563-33568.

14. Kops, G. J., Weaver, B. A., Cleveland, D. W. (2005) On the road to cancer: aneuploidy and the mitotic checkpoint. Nat. Rev. Cancer 5, 773-785.

15. Kraniak, J. M., Abrams, J., Nowak, J. E., Tainsky, M. A. (2006) Antioxidant agents transiently inhibit aneuploidy progression in Li-Fraumeni cell strains. Mol. Carcinog. 45, 141-156.

16. Kushnirov, V. V. (2000) Rapid and reliable protein extraction from yeast. Yeast (Chichester, England). 16, 857-860.

17. Lau, D. T., Murray, A. W. (2012) Mad2 and Mad3 cooperate to arrest budding yeast in mitosis. Curr. Biol. 22, 180-190.

18. Lawrence, K. S., Engebrecht, J. (2015) The spindle assembly checkpoint: More than just keeping track of the spindle. Trends. Cell. Mol. Biol. 10, 141-150.

19. Liou, G. Y., Storz, P. (2010) Reactive oxygen species in cancer. Free Radic. Res. 44 $10.3109 / 10715761003667554$ 
20. Madeo, F., Fröhlich, E., Ligr, M., Grey, M., Sigrist, S. J., Wolf, D. H., Fröhlich, K. U. (1999) Oxygen stress: a regulator of apoptosis in yeast. J. Cell Biol. 145, 757-767.

21. Magenta, A., Fasanaro, P., Romani, S., Di Stefano, V., Capogrossi, M. C., Martelli, F. (2008) Protein phosphatase 2A subunit PR70 interacts with pRb and mediates its dephosphorylation. Mol. Cell. Biol. 28, 873-882.

22. Michel, L. S., Liberal, V., Chatterjee, A., Kirchwegger, R., Pasche, B., Gerald, W., Dobles, M., Sorger, P. K., Murty, V. V., Benezra, R. (2001) MAD2 haplo-insufficiency causes premature anaphase and chromosome instability in mammalian cells. Nature 409, 355-359.

23. Mukhtar, E., Adhami, V. M., Mukhtar, H. (2014) Targeting Microtubules by Natural Agents for Cancer Therapy. Mol. Cancer Ther. 13, 275-284.

24. Musacchio, A. (2015) The Molecular Biology of Spindle Assembly Checkpoint Signaling Dynamics. Curr. Biol. 25, R1002-1018.

25. Pelicano, H., Carney, D., Huang, P. (2004) ROS stress in cancer cells and therapeutic implications. Drug Resist. Updat. 7, 97-110.

26. Pérez de Castro, I., de Cárcer, G., Malumbres, M. (2007) A census of mitotic cancer genes: new insights into tumor cell biology and cancer therapy. Carcinogenesis 28, 899-912.

27. Roh, M., Abdulkadir, R., van der Meer, S. A. (2012) Tumorigenic polyploid cells contain elevated ROS and ARE selectively targeted by antioxidant treatment. J. Cell. Physiol. 227, 801-812.

28. Schieber, M., Chandel, N. S. (2014) ROS Function in Redox Signaling and Oxidative Stress. Curr. Biol. 24, R453-R462.

29. Shapira, M., Segal, E., Botstein, D. (2004) Disruption of yeast forkhead-associated cell cycle transcription by oxidative stress. Mol. Biol. Cell 15, 5659-5669.

30. Stobbe, C. C., Park, S. J., Chapman, J. D. (2002) The radiation hypersensitivity of cells at mitosis Int. J. Radiat. Biol. 78, 1149-1157.

31. Stukenberg, P. T., Burke, D. J. (2015) Connecting the microtubule attachment status of each kinetochore to cell cycle arrest through the spindle assembly checkpoint. Chromosoma 124, 463-480.

32. Tominaga, H., Kodama, S., Matsuda, N., Suzuki, K., Watanabe, M. (2004) Involvement of reactive oxygen species (ROS) in the induction of genetic instability by radiation. J. Radiat. Res. 45, 181-188.

33. van de Wetering, C. I., Coleman, M. C., Spitz, D. R., Smith, B. J., Knudson, C. M. (2008) Manganese superoxide dismutase gene dosage affects chromosomal instability and tumor onset in a mouse model of T cell lymphoma. Free Radic. Biol. Med. 44, 1677-1686.

34. Varbiro, G., Veres, B., Gallyas, F. Jr., Sumegi, B. (2001) Direct effect of Taxol on free radical formation and mitochondrial permeability transition. Free Radic. Biol. Med. 31, 548-558.

35. Wang, C. Y., Liu, L. N., Zhao, Z. B. (2013) The role of ROS toxicity in spontaneous aneuploidy in cultured cells. Tissue Cell 45, 47-53.

36. Wang, G. F., Dong, Q., Bai, Y., Yuan, J., Xu, Q., Cao, C., Liu, X. (2017) Oxidative stress induces mitotic arrest by inhibiting Aurora A-involved mitotic spindle formation. Free Radic. Biol. Med. 103, 177-187.

37. Wang, Q., Liu, T., Fang, Y., Xie, S., Huang, X., Mahmood, R., Ramaswamy, G., Sakamoto, K. M., Darzynkiewicz, Z., Xu, M., Dai, W. (2004) BUBR1 deficiency results in abnormal megakaryopoiesis. Blood. 103, 1278-1285.

38. Weaver, B. A., Cleveland, D. W. (2006) Does aneuploidy cause cancer? Curr. Opin. Cell Biol. 18, 658-667. 